\title{
Study of Negative Symptoms among 100 Schizophrenic Patients
}

\author{
Bhuiyan $\mathrm{AP}^{1}$, Islam $\mathrm{MA}^{2}$, Islam $\mathrm{MM}^{3}$, Hasin $\mathrm{A}^{4}$ \\ DOI: https://doi.org/10.3329/jafmc.v17i1.56716
}

\begin{abstract}
Introduction: Schizophrenia is a clinical syndrome of variable but profoundly disruptive, psychopathology that involves cognition, emotion, perception and other aspects of behavior. The expression of these manifestations varies across patients and over time, but the effect of the illness is always severe and usually long lasting. The disorder usually begins before age 25 , persists throughout life, and affects persons of all social classes. Both patients and their families often suffer from poor care and social ostracism because of widespread ignorance about the disorder. Schizophrenia is equally prevalent in men and women.
\end{abstract}

Objective: To find out the pattern and frequency of negative symptoms in Schizophrenic patients.

Materials and Methods: This descriptive cross-sectional study was conducted from 1st June to 31st December 2014 among 100 schizophrenic patients. For demographic assessment every patient was interviewed by a semi-structured questionnaire, after taking informed consent. Scale for the Assessment of Negative Symptoms (SANS) was used to interview the Schizophrenic patient. The scale is internationally well accepted research instrument for assessing negative symptoms in Schizophrenic patient. The study was conducted in Combined Military Hospital (CMH), Dhaka, National Institute of Mental Health (NIMH), Dhaka and Bangabandhu Sheikh Mujib Medical University (BSMMU), Dhaka. Sampling size was 100 where Schizophrenia was diagnosed by psychiatrists.

Results: The age group of the patients was from 18 years to 59 years with mean age 27.3 years ( $S D \pm 11.0$ ), most of the patients were below the age of 30 years. Eighty six (86\%) out of one hundred patients were found to have negative symptom. Most of the patient were male, literate, Muslim and came from a middle class family background. Onset of the disease was mostly insidious in nature.

Conclusion: Schizophrenia is a major psychiatric disorder. Both the patient and their families suffer a lot by schizophrenia and its consequences. So improving the management of negative symptoms may reduce the overall burden of schizophrenic patients and their caregivers.

Key-words: Negative Symptoms, Schizophrenia, Scale for the assessment of negative symptoms.

\section{Introduction}

Schizophrenia is the heartland of psychiatry and the core of its clinical practice. Schizophrenia means 'Split mind' and this concept of madness is largely based on the oddities and abnormalities of those who suffer from this enigmatic illness. It is a relatively common psychiatric disease, which often cripples people in adolescence or early adult life, it probably means more suffering, distress and blights more lives than any cancer. Because it cripples people in their youth without greatly reducing their life expectancy it constitutes a huge burden on health services ${ }^{1}$. Schizophrenia is among the top 10 disabling conditions worldwide among young adults ${ }^{2}$. In the USA, the cost of treatment and loss in productivity associated with schizophrenia are estimated to be as high as $\$ 60$ billion annually ${ }^{3}$. For a long time, research efforts in schizophrenia were generally directed toward improvement of positive symptoms, those that are more directly related to the safety of the patient and around him or her. However, negative symptoms are undoubtedly critical to a patient's quality of life and particularly crucial to his or her social life ${ }^{4}$. Negative symptoms which include a motivation, a flattening of emotional response, a reduction in speech and activity and social withdrawal5. These symptoms are also associated with poor psychosocial functioning ${ }^{6}$. The etiology and pathophysiology of negative symptoms are unknown and there are no effective treatment ${ }^{7,8}$.

\section{Materials and Methods}

This descriptive cross-sectional study was conducted from 1st June to 31st December 2014 among 100 schizophrenic patients diagnosed by Psychiatrist. Purposive consecutive sampling method was applied. For demographic assessment, every patient was interviewed by a semi-structured questionnaire after taking informed consent. Scale for the Assessment of Negative Symptoms (SANS) was used to assess the negative symptoms of Schizophrenia. SANS is split into 5 domains (Affective flattening, Alogia, Avolition-apathy, Anhedonia and Attention) and within each domain separate symptoms are rated from 0 (Absent) to 5 (Severe). The study was conducted in Combined Military Hospital $(\mathrm{CMH})$, Dhaka, National Institute of Mental Health (NIMH) Dhaka and Bangabandhu Sheikh Mujib Medical University (BSMMU), Dhaka. Statistical Package for Social Science (SPSS), version 15. Tests of significance were applied at $95 \%$ confidence interval level. Results were presented as text, tables and figures.

1. Maj Anwar Parvez Bhuiyan, MBBS, FCPS, Classified Specialist in Psychiatry, Border Guard Hospital, Dhaka (E-mail: parvez101293@gmail.com) 2. Brig Gen Md Azizul Islam, MBBS, FCPS, FRCP (Glasgow), FACP (USA), Ex-Advisor Specialist in Psychiatry, CMH, Dhaka 3. Lt Col Md Monirul Islam, MBBS, FCPS, Classified Specialist in Psychiatry, CMH, Ghatial 4. Dr. Atiyah Hasin, BDS, MS (PHASE-B), Trainee in BSMMU, Dhaka. 


\section{Results}

Age distribution of the patients showed from 18 years to 59 years with mean age 27.3 years, $S D \pm 11.032,37 \%$ belonged to the below 20 years age group and $32 \%$ from $21-30$ age group. Regarding sex distribution of the patients $77 \%$ were male and $23 \%$ were female. Among the 100 patient $86 \%$ patients were Muslim, 12\% Hindu, 1\% Christian and 1\% Buddhist. According to their marital status, 51\% patients were married and $49 \%$ unmarried. $38 \%$ patients were come from urban and $62 \%$ come from rural background. Most of the patients were literate (Figure-1). According to the onset of the disease $78 \%$ patient had insidious onset of disease and $22 \%$ had sudden onset.In this study $86 \%$ patient had no family history of psychiatic illness. Schizophrenic patients may present with predominant positive symptoms or predominant negative symptoms. In this study shows $86 \%$ patient have at least one negative symptom and $14 \%$ have no negative symptoms. Mean score of SANS of 100 patients in this study was 32.1, SD \pm 15.7 with 95 confidence interval (Figure-2). There are five domains in scale for the assessment of negative symptoms. Mean score in Affective flattening 8.9, Alogia 8.0, Avolition-apathy 7.4, Anhedonia 6.5 and Attention 1.9 (Figure-4). Table-I shows that 22\% patient had sudden onset of the disease and $78 \%$ had insidious onset. There was highly significant association between the type of onset of the disease and negative symptoms. Table-II shows more negative symptoms present in long duration (37-42 months) of illness. Negative symptoms increase with duration of illness.

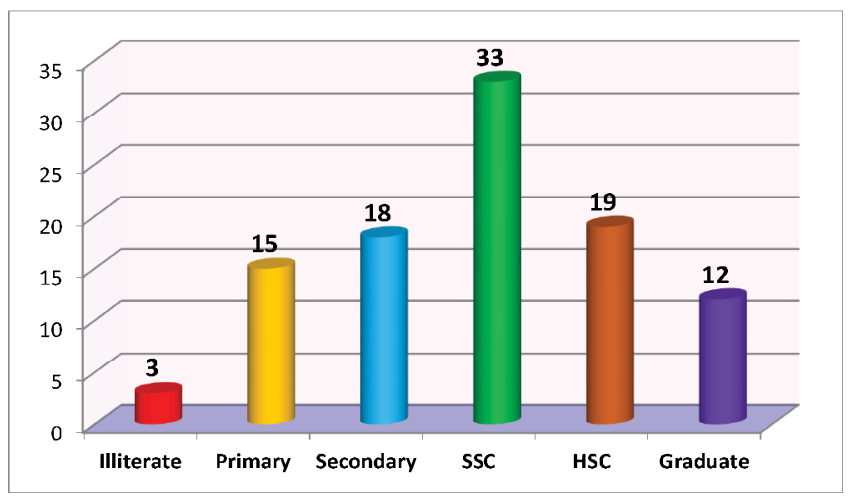

Figure-1: Distribution of patients according to their educational background $(n=100)$.

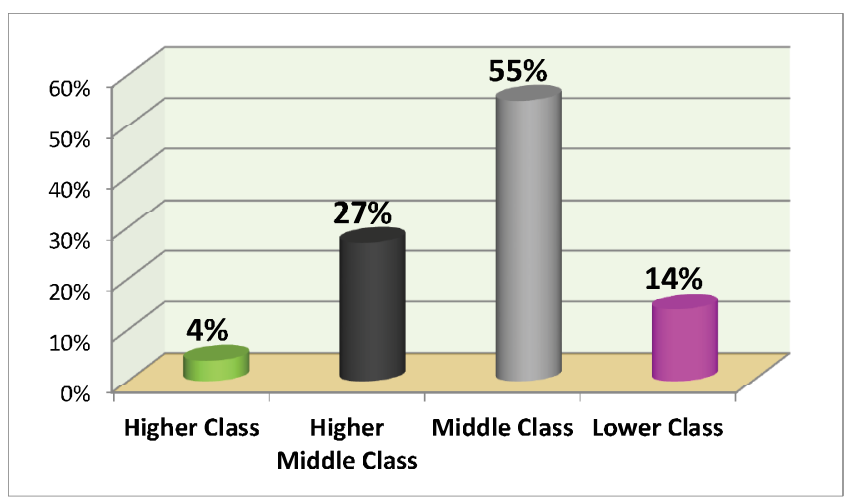

Figure-2: Distribution of patients according to their ecoomic status.

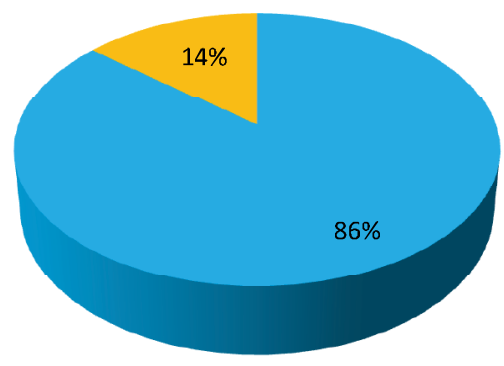

At least 1 negative symptom No negative symptom

Figure-3: Distribution of patients according to the frequency of negative symptoms.

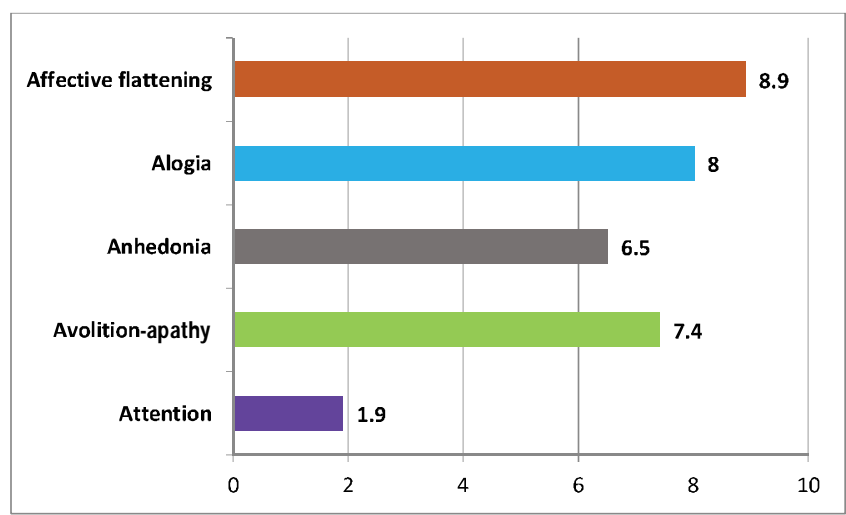

Figure-4: Frequency of negative symptoms.

Table-l: Distribution of negative symptoms according to onset of the disease $(n=100)$

\begin{tabular}{|l|c|c|c|}
\hline $\begin{array}{c}\text { Onset of } \\
\text { the } \\
\text { disease }\end{array}$ & $\begin{array}{c}\text { Negative } \\
\text { symptoms } \\
\text { present }\end{array}$ & $\begin{array}{c}\text { Negative } \\
\text { symptoms } \\
\text { absent }\end{array}$ & Total \\
\hline Sudden & 21 & 1 & 22 \\
\hline Insidious & 65 & 13 & 78 \\
\hline Total & 86 & 14 & 100 \\
\hline
\end{tabular}

Table-II: Distribution of negative symptoms according to the duration of illness $(n=100)$.

\begin{tabular}{|c|c|c|c|}
\hline Duration & $\begin{array}{c}\text { Negative } \\
\text { symptoms } \\
\text { present }\end{array}$ & $\begin{array}{c}\text { Negative } \\
\text { symptoms } \\
\text { absent }\end{array}$ & Total \\
\hline $\begin{array}{c}\text { Below 6 } \\
\text { months }\end{array}$ & 1 & 0 & 1 \\
\hline $\begin{array}{c}7-12 \\
\text { months }\end{array}$ & 1 & 0 & 1 \\
\hline $\begin{array}{c}13-18 \\
\text { months }\end{array}$ & 1 & 1 & 2 \\
\hline $\begin{array}{c}19-24 \\
\text { months }\end{array}$ & 2 & 0 & 2 \\
\hline $\begin{array}{c}25-30 \\
\text { months }\end{array}$ & 8 & 0 & 8 \\
\hline $\begin{array}{c}31-36 \\
\text { months }\end{array}$ & 31 & 3 & 34 \\
\hline $\begin{array}{c}37-42 \\
\text { months }\end{array}$ & 42 & 10 & 52 \\
\hline Total & 86 & 14 & 100 \\
\hline
\end{tabular}




\section{Discussion}

Schizophrenia is a major psychiatric disorder which is still now burden to the family and also to the country. Due to repeated relapse of schizophrenia, functional, social and occupational activities gradually deteriorate and ultimately lead to defect state. Thus the schizophrenic patients become burden to the family, society and state as well. In current study eighty six (86\%) out of 100 patients were found to have at least one negative symptom. In this study most prevalent negative symptom in schizophrenic patients was affective flattening. One Indian study found $87.5 \%$ have at least one negative symptoms and most prevalent negative symptom was affective flattening ${ }^{9}$. The age of the patients included in this study ranged between 18 years to 59 years with mean age 27.3 years $S D \pm 11.0$. Most of the patients were below the age of 30 years. Though it is the mean age of study population, it falls between age ranges of schizophrenia ${ }^{10,11}$. According to gender distribution, maximum patients were male (77\%). Several studies in different country revealed maximum patient were male ${ }^{12-16}$. In this study $51 \%$ sample were unmarried and $49 \%$ were married. Several study in different country revealed same result ${ }^{13,14}$.

In this study, majority of patients were literate; Primary (15\%), Secondary (18\%), SSC (33\%) and higher education (12\%). In Iraq, Shaker AS found primary (28\%), secondary (14\%), SSC (26\%) and higher education (7\%) in his study ${ }^{16}$. These study findings consist with that Iraqi study finding. In present study, maximum patients were service holder (42\%). This may be explained as the Combined Military Hospital (CMH) is a service hospital only for armed forces personal. And all the study places were located in the metropolitan area. Regarding economical status of patients, $55 \%$ patients were from middle class and $14 \%$ patients were from lower economical status. This may also explained as among three tertiary hospitals one is service hospital and all three hospitals located in metropolitan area.

According to social background, maximum schizophrenic patients were from urban area (62\%). The study of mental disorder in urban areas by Faris and Dunham were found $96 \%$ patient from urban areas. Selective factors like location of hospital in the urban areas, economical factor and health consciousness about the mental health service explain the preponderance of the urban patients ${ }^{17}$. In this study, $86 \%$ of patients have no positive family history of psychiatric illness and $14 \%$ of patients have positive family history of psychiatric illness. Several study conducted in different countries found no positive family history of psychiatric illness ${ }^{11,16}$.

Significant association was also found between the onset of the disease and negative symptoms. In this study, $78 \%$ of patients have insidious onset of disease. This study findings consistent with other some study findings ${ }^{11,18}$. In this study, Affective flattening is the most frequent negative symptom in the schizophrenic patient. It is also consistent with other study which was done in Bangladesh ${ }^{19}$. Negative symptoms have insidious onset, poor outcome, poor response to antipsychotic drugs. One study has suggested that the presence of negative symptoms in early in the course of the illness predicts a poor outcome. Cognitive impairment tends to be minimal when positive symptoms are prominent, but negative symptoms may be associated with severe cognitive impairment. It also causes social and occupational impairement ${ }^{20}$.

\section{Conclusion}

The schizophrenic patients with negative symptoms less visit clinicians because negative symptoms are less visible and not easily draw attention to the caregiver or relatives of the patients. The treatment options for negative symptoms are extremely limited. Negative symptoms in patient with schizophrenia predict poor social outcome. Various treatment strategies have been studied, in which several types of medications were added to antipsychotics in order to alleviate negative symptoms. So, effective management of negative symptoms may reduce the overall burden of schizophrenic patient.

\section{References}

1. Kendell RE, Zealley AK. Companion to the Psychiatric Studies, 5th ed, 1995:397-423.

2. Wu EQ, Birnbaum HG, Shi $L$ et al. The economic burden of schizophrenia in the United States in 2002. J Clin Psychiatry. 2005; 66:1122-9.

3. Trauer T, Duckmanton RA, Chiu E. Estimation of costs of public psychiatric treatment. Psychiatr Serv. 1998; 49:440-2.

4. Bobes J, Arango C, Garcia M et al. Prevalence of Negative Symptoms in Outpatients with Schizophrenia spectrum Disorder Treated with Antipsychotics in routine clinical practice: Findings from the CLAMORS Study. J Clin Psychiatry. 2010; 71(3):280-6.

5. Foussias G, Agid O, Remington G. Handbook of schizophrenia spectrum disorders, volume II. Dordrecht: Springer Netherlands, 2011.

6. Rabinowitz J, Berardo CG, Bugarski-Kirola D et al. Association of prominent positive and prominent negative symptoms and functional health, well-being, healthcare-related quality of life and family burden: A CATIE analysis. Schizophr Res. 2013; 150:339-42.

7. Arango C, Garibaldi G, Marder SR. Pharmacological approaches to treating negative symptoms: A review of clinical trials. Schizophr Res. 2013; 150:346-52.

8. Fusar-Poli P, Papanastasiou E, Stahl D et al. Treatments of negative symptoms in schizophrenia: Meta-analysis of 168 randomized placebo-controlled trials. Schizophr Bull. 2014; 41:892-9.

9. Bambole V, Shah N, Sonavane S et al. Study of negatives symptoms in first episode schizophrenia. Open journal of Psychiatry. 2013; 3:323-28.

10. Cowen P, Harrison P, Burns T. Shorter Oxford Textbook of Psychiatry.6th edition. United Kingdom: Oxford university press; 2012.

11. Bashar K, Firoz AHM, Mandal MC et al. Socio-demographic 
parameters and quality of life of schizophrenic patients. Bang J Psychiatry. 2008; 22(2):18-27.

12. Mazumder AH, Alam MT, $\mathrm{H}$ Yoshii et al. Positive and Negative Symptoms in Patients of Schizophrenia: A Cross Sectional Study. Acta Medica International. 2015; 2(1):48-52.

13. Patel $R$, Jayatilleke $N$, Broadbent $M$ et al. Negative symptoms in schizophrenia: A study in a large clinical sample of patients using a novel automated method. BMJ Open. 2015; 5(9):e007619.

14. Abo El, Ella El, Hasim NZ et al. Negative symptoms and functioning in institutionalized versus outpatient schizophrenic patients. Middle East Current Psychiatry. 2015; 22:65-9.

15. Karim ME, Mullick MSI, Habib MA. Effect of season of birth on schizophrenia. The Journal of Teachers Association, Rajshahi Medical College. 1995; 8(2):55-7.
16. Shaker AS. Prevalence of Negative Symptoms in Chronic Long Stay Schizophrenic Patients at AL-Rashad Mental Teaching Hospital. The Iraqi Postgraduate Medical Journal. 2011; 10(3):414-20.

17. Faris REL and Dunham HW. Mental disorders in urban areas: An ecological study of schizophrenia and other psychoses. Am J Public Health Nations Health. 1960; 50(9):1455.

18. Crow TJ. Molecular pathology of schizophrenia: More than one disease process? British Medical Journal. 1980; 280:66-8.

19. Mazumder $\mathrm{AH}$, Kortesluoma RL, Yoshii $\mathrm{H}$ et al. Positive versus negative symptoms of Schizophrenia in a tertiary level hospital in Banglades. Bangladesh Journal of Psychiatry. 2011; 25(2):63-71.

20. Islam T, Firoz AHM, Sobhan MA. Schizophrenia: Clinical presentation and brain mechanism- A Review Article. Bangladesh Journal of Psychiatry. 1996; 9(1):48-51. 